\title{
The New Mythologies and Premature Aging in the Youth Culture
}

\author{
David Gutmann ${ }^{1}$
}

Received February 19, 1973

\begin{abstract}
Comparative studies of aging men in a variety of preliterate traditional societies suggest that older men, across cultures, are relatively mild and uncompetitive, as compared to younger men from the same communities. Older men are more interested in receiving than in producing, more interested in communion than in agency; their sense of pleasure and security is based on food, religion, and the assurance of love. The counterculture gives priority to the same themes, and thereby seems to sponsor a premature senescence, in the psychological sense. Various contemporary myths stemming from affluence and consumerism that have led to the new geriatrics are examined, particularly the myth of the all-including, omnipotential self, which is seen as a translation of socialist, collectivist ideals into the domain of personality. The effects of the new psychic collectivism on ego development in the adolescent and postadolescent periods are also considered.
\end{abstract}

\section{AGING MEN AND PRESENILE YOUTH}

This article discusses identity problems in adolescence and postadolescence-topics about which I have little expert knowledge. Quite the contrary, my particular expertise has to do with the psychology of the aging, at the other end of the life cycle. Thus for the past 8 years I have been carrying out cross-cultural research in traditional and usually preliterate societies in an attempt to develop some basis for a comparative psychology of aging. However,

The overall program of cross-cultural research has been supported by Career Development Award No. 5-K3-Hd-6043 from the National Institutes of Child Health and Human Development. Field expenses for Indian studies in Mexico and America were covered by Faculty Research Grants Nos. 1344 and 1412 from the Rackham School of Graduate Studies, the University of Michigan, and by Grant No. MH 13031-01 from the National Institutes of Mental Health. Fieldwork expenses among the Middle-Eastern Druze were covered by Grant No. M66-345 from the Foundation's Fund for Research in Psychiatry.

${ }^{1}$ Department of Psychology, University of Michigan, Ann Arbor, Michigan. Professor of Psychology at the University of Michigan. Received Ph.D. in 1959 from the Committee on Human Development at the University of Chicago. Main fields are clinical psychology and personality theory. Research interests are comparative psychology of aging and psychosocial aspects of ego development. 
the discrepancy between the topic of this paper and my usual interests may not be as great as it first seems. That is, it now appears that there are more than accidental parallels between what might be called the "species" dimensions of aging psychology and the themes of the emerging adolescent and postadolescent youth culture, or counterculture. In their motives, their behaviors, and their "New Morality," the more alienated young males of our society are coming to resemble the old men of the traditional societies that I have studied much more than they resemble their own age peers of such societies. Accordingly, I will preface the discussion of current trends in adolescent morality and identity with some observations on the normal psychology of aging.

A note on how these observations were developed: They are based on intensive interviews with older men from the traditional Navajo, the Lowland and Highland Maya, and the Middle Eastern Druze societies. At each site, the interviews have covered important life issues, particularly those identified by the subjects themselves, and have included projective tests. Comparing the data generated by younger men to those generated by older men, I find age differences which tend to be consistent across the panel of subject societies and which parallel those found originally among urban middle-class Americans (Gutmann, 1964, 1966, 1967, 1969, 1971; Krohn and Gutmann, 1971; Goldstine and Gutmann, 1972). Being standard, these age differences suggest a developmental ' continuum, and the developmental implications have been supported by the results of recent follow-up studies with the original panel of Druze and Navajo subjects (Gutmann, 1972b).

Turning briefly to some of the major findings, it is very clear in all data from all cultures that older men are less aggressive than younger men; they are more affiliative, more interested in love than in conquest or power, more interested in community than in agency. The younger men see energy within themselves, as a potential threat that has to be contained and deployed to productive purposes. But the old men see energy as outside of themselves, lodged in capricious secular or supernatural authorities; as they see it, their job is to come to terms with such authorities, to insure that their power will not harm them, or that it will be used for their benefit. For the older men, power is manipulated and controlled in its external form through prayer and other forms of supplication and accommodation. As the younger men see it, their job is to create and gain control of resources, for the benefit of themselves and their dependents. But the older men see themselves in the position of the dependent: for them, supplies and resources are seen to be beyond their control, and the agents who possess the vital resources are placated and appeased. Thus in order to insure his well-being the old man apprehends the wishes of the authorities and puts himself in harmony with them. 
Consistent with this age-graded switch to a more dependent and affiliative position, there is also later in life the turn toward diffuse sensuality. In the main, younger men are businesslike: they do not go out of their way to seek pleasure, nor do they avoid necessary discomfort. They mainly seek pleasure in sex, at night, when work is done (and even their sexual pleasures have a productive goal: they are in the service of procreation). Older men by contrast are more diffusely sensual, more sensitive to the incidental pleasures and pains of the world. Unlike the "phallic" younger men, the older men seek pleasure in the pregenital direction: they become particularly interested in food, also in pleasant sights, sounds, and human associations. Where younger men look at the world instrumentally, older men take some incidental bonus of esthetic pleasure from their daily routines.

We also find, across a wide range of cultures, that women age, psychologically speaking, in the reverse direction. Even in normally patriarchal societies, women become more aggressive, less sentimental, and more domineering-they became less interested in communion and more turned toward agency. Thus over time and across sex lines a massive transcultural involution takes place, wherein women become more like what their husbands used to be and older men become more like what their wives used to be. With this development, there is ushered in the normal unisex of later life.

Perhaps as part of their "feminization," older men tend to become more religious. They now relate to the gods in a profoundly submissive fashion. The swing to religion among older men seems to be based on their need to please the gods and to submit to them, but it is also based on a weakening or fraying-out of ego boundaries; the older men come to feel, quite directly, that they are included in or incorporated by the great and productive powers of the universe.

This later-life diffuseness of ego boundaries permits the religious experience, and it also sponsors a tendency to fall back on the ego position of "Magical Mastery," particularly in times of trouble and confusion. For the older men, wishes begin to dominate perception; they begin to rely heavily on the rather primitive ego defenses of denial and projection. They find in the external world either what they want to see or what they fear to discover within themselves. For the older men, the world becomes-particularly in times of confusion and ambiguity-a picture of the inner states that are aroused by their dealings with the world. Thus it is not only behavior and motives which shift with later life in the passive direction; the structures and processes of the ego are also deprived of sustaining energy, and the ego is less able to maintain neutral, conflict-free areas of function.

As I assembled this composite picture of the gentle, sensual, mystical old man-the "species-typical" old man-it struck me that I was not only describing 
the aged, but also hippies, the New Youth of the counterculture. ${ }^{2}$ It struck me that the "Greening of America" might really be the "Greying of America." Thi: was an accidental, unexpected finding; but I was still very impressed with the degree to which the characteristics that normally distinguish older from younger men had become the announced morality and politics of the counterculture. Accordingly, in a recent article I have referred to the counterculture as a "premature gerontocracy" (Gutmann, 1972a). As I stated there, "the counterculture, its theorists and public relations men have co-opted, as the very badge of youth and renewal, those qualities which are the species insignia of aging."

A major parallel between the counterculture and the Country of Old Men has to do with their common stance toward competitive strivings. In the morality of the counterculture, such strivings are also defined as dangerous, and even as a source of original sin; and in backing away from the competitive stance the new youth have, like the aged, elevated communion above agency. Consistent with this, Norman O. Brown (1959) and Herbert Marcuse (1962)-two aging Gurus-have insisted that the polymorphous-diffuse erotic style that is common to the aged is the ideal goal of erotic development generally, and should serve as a model for youth. And, indeed, we find that the message has been heeded: despite much rhetoric about the "Sexual Revolution," we find that diffuse sensuality, rather than genital sexuality, has become the preferred style of the counterculture. As a matter of fact, the new morality in its sexual aspect has led to what Esquire Magazine recently called the "New Impotence" and to what Midge Decter (1972) has called the "New Chastity." Thus we find a great deal of emphasis on the pleasures of feeling, of massaging, groping, and oral sex. Furthermore-just as with the aged-we find an erotization of the visual functions. The creativity of the counterculture is mainly centered around visual arts: posters, movies, light shows, hallucinations. In line with this general concentration on pregenital pleasures, we find the predictable interest in food, particularly natural foods, macrobiotic diets, candy, and sweet wines. The largest amount of shelf space in any university bookstore is now taken up with cookbooks of various sorts, and the recent Commune Cookbook states quite explicitly that "rural communes prove to be centered not on lurid sex or violent politics, but on food." Indeed, the tie to food is so symbiotic, so charged, that pure foods or natural foods are viewed in the counterculture as the essential

${ }^{2}$ I cannot be very specific as to what is meant by "counterculture" (substitute "hippies" if you need a more concrete referent, but the boundaries of that group have also become very blurred). I am referring to that admittedly amorphous, always changing cohort, mostly young, composed of those who live in opposition to an official "establishment" culture which reputedly emphasizes the values of competition, industry, and the consumption of mass-produced goods. Though New Left activists also belong to the counterculture, they are not included in the comparisons that are here sketched out between old men and contemporary youth. The militants do share many of the values of the more passive and pacifistic hippies, but they are active and instrumental in trying to create the social conditions under which such values could presumably flourish. 
guarantors of a pure and natural self. In previous versions of morality, one was usually instructed to rise above the appetites; in the morality of the counterculture, appetite is the basis of morality.

In the counterculture, the morality of hedonism is also tied to the morality of unisex. My old subjects are likely to admit, rather grudgingly, that they depend on their wives and that their wives might even dominate them. They do not, however, elevate this development into a cause or into a politics. But in the counterculture, the boundaries, the usual sex role distinctions, between men and women are explicitly condemned: young men seem to be exploring the possibilities of empathy, tenderness, and receptive sex, while young women dress in jeans, swear off cosmetics, and hike out on their various vision quests, intent on proving their manhood. Again, as with the aged, dependency on emotional supplies is generally sponsored in the counterculture. Riesman's "Lonely Crowd" has become the Lonely T-Group. The traditional sex role distinctions in regard to succorance are reversed, and men are instructed to be dependent rather than phallic-i.e., "sexist"-toward their girlfriends. In any event, the shift toward unisex, which normally comes about in later life, and after parental tasks are completed, now occurs before the onset of parenthood. Biological reproduction continues in the counterculture, but it begins to mobilize what has up to now been a postparental or even grandparental attitude. We do not yet know the consequences-good or bad-of this shift for children. But it is safe to assume that there will be some.

Finally, as in the country of old men, we find the intense religious emphasis of the counterculture which has most recently taken the form of the "Jesus Freak" phenomenon. And it should be remembered that most of the religious orientations now practiced by the new youth-Eastern mysticism, astrology, food cults, and the like-were pioneered for them by hysteroid old ladies in California. The religiosity of youth seems to be founded, as with the aged, on magical mastery: it represents the attempt to become allied with the excellent and productive forces of the universe. The main difference is that the aged seek this unity, this harmony, through ritual means provided by an organized religion, while the young find this sense of harmony through various means which artificially reduce ego boundaries: hard and soft drugs, rhythmic chanting, meditation, and frenzied dancing. In later life, the ego boundaries erode naturally, as sustaining energy is withdrawn from them, but among youth they must be reduced violently, through a kind of revolutionary act. That is, in their attempt to elevate magical mastery to a dominant style before its usual season, the people of the counterculture make the ego their explicit enemy and they turn against all its functions of rationality, boundary maintenance, linearity, and future orientation. Consistent with the elevation of magical mastery, denial and projection become-as in later life-the main defensive motifs of the counter culture. Thus in a classic instance of denial, the youth culture claims that a pure, aggression-free, loving self will mobilize a loving 
response from the world, that nature is somehow resonant to human motive and purpose, and that, in effect, there is "someone up there who loves you." Furthermore, in the paranoid direction, the world is divided into the "camp of life"-those who abhor aggression or are the targets of aggression-and the "camp of death"-those who practice aggression and seek power over nature or over other men. Anger is repressed, but finds its way back into the counterculture via projection and institutionalized paranoia: violence by the camp of life is justified if it is directed against the camp of death.

\section{THE NEW MORALITY AND THE NEW SOCIALISM}

It is hard to find a morality as such at work in a culture that declares itself against the kinds of restrictions and demands on the instincts that usually constitute a morality. However, to the degree that there is a moral dimension in the new culture, I think we can safely say that it has two major elements: it is anti-aggressive, and it is anti-instrumental. That is, it condemns as immoral and even "deathlike" the restrictions that individuals who serve the achievement motive must put on feeling, on sensation, and on spontaneous, impulsive action.

We can understand why aged men might turn away from instrumentality, and away from the productive, generative orientation that is essential to parenthood. In their case, the period of chronic emergency that we call parenthood is ended, their skills tend to be outmoded, and they can now rely on their grown children for support. Their species and social dues have been paid, and they can retire with good conscience to the cultivation of their gardens and the mild pleasures of the table, of sociability, and of meditation. Jung remarked, "The latter half of life is compensatory for the first." Thus old men can live out some of the potentials, sensual and emotional, that they once had to repress in the service of production and parenthood; furthermore, they can withdraw some of the energy that went into maintaining the ego boundary structures on which instrumentality is founded. (By the same token, older women can repossess some of the aggression that they once had to deny themselves in the service of the maternal role.) The aged are postproductive and have earned the right to a more self-indulgent style of life; but on what grounds do youth so eagerly turn to a life style that in the normal course of human events is the badge of aging? This question is partially answered when we consider that, in an affluent urban society, youthful productivity is not much required. In primitive and preliterate societies, those that exist under hardship conditions, the young are almost universally taught that they cannot be lazy, that they have to learn to work, and that in the future they and their children will have to rely on skills and on character traits that are developed in childhood. Their achievements in these terms are tested in puberty rituals: the candidate is exposed to pain, terror, or isolation, and he shows that he is ready to be a man by not crying for his 
mother. Clearly, our youth get very little of such messages, or of such tests. Accordingly, they do not have the usual incentive to impose the restrictions, the self-denials that are necessary to future accomplishment and self-maintenance. Psychologically speaking, they remain in the preproductive position, they turn against the instrumental life, and the psychological consequences of that rejection are much the same in their case as they are in later life. Young people who reject instrumentality may do so in the name of liberation, but it appears that they bind themselves to consequences which are as predictable and as fixed as those that are contingent on the opposite choice of a hardworking and competitive existence: namely, diffuse sensuality, unisex, reliance on illusion, vague religiosity, and so forth.

The foregoing explanation has the virtue of being obvious, and therefore quite possibly correct, and it makes sense of the observed correspondence between the psychological position of the young elites and the aged men. However, there are also important differences between the people of the counterculture and the normal aged that should not be overlooked, and that cannot be clarified by a set of ideas that purports to explain the similarities between these cohorts. For one thing, there is a messianic and revolutionary fervor about the new culture-even in the defense of their passivity-that is not found among the aged, who tend to be apologetic about their life style. The young proselytize and politicize their version of the antiproductive style, and this enthusiasm argues for the existence of other, more inspired motives, beyond the simple wish to take life easy or to drop out of the rat race. The new culture is after all buttressed by a new morality, and one that is more than a rationale for the new passivity. While many of the New Youth use their morality to rationalize their hedonism, there are also many who adopt hedonism in an almost compulsive fashion, in the service of their adopted morality. Morality is intimately related to the mythic dimensions of existence: moral behavior is in effect the enactment, within the mundane, daily life, of the mythic principles-it relates the ordinary human to the domain of the gods. Accordingly, the appearance of a new morality argues the presence of new myths, potent enough to capture the imagination and to mobilize the revolutionary fervor of a large segment of the young. I would argue that the myths that organize and that drive the new morality are of the same order as those that vitalized the socialist movements for earlier generations of youth. The old socialist myth proclaimed a perfect order of society, of brotherhood to be achieved through the revolution of the proletariat; that new order would not have to be constructed, but would be revealed, uncovered, when the decadent structures of capitalist society were removed by revolutionary action. The new mythology still holds to the idea of a discoverable perfection, but gives it a new locus, not in the socialist society but within the "natural," unsocialized self. The new version of the myth reads: "Somewhere within me, already formed, there is a domain of wholeness, of vital 
energy, of organic wisdom, of all possibilities and potentials." This perfection does not have to be created; it is there, already formed and waiting for the liberating action that will disperse the boundaries that a corrupt society has set between the mundane self and its reservoir of internal perfection. The Marxists believed that socialism in its communal sense would bring the final perfection, the final integration in which all opposites would be contained and reconciled: Power would combine with brotherhood; the goals of the self would be one with the goals of the collectivity. The new revolutionaries believe this of their own inner life. It is only the ego-the outpost of the establishment within one's head-that keeps one from experiencing this treasury of possibilities.

I suggest then that the myths that drive and sustain the new morality are the transformed myths of socialism-the socialism of the affluent. The new morality has mainly been taken up by the affluent children of a parental generation that has become disillusioned with traditional socialism and that has to some degree overcome the pragmatic, physical limitations of life. The parents, and their children through them, have tested the possibilities of material well-being and of material possession. For both generations, material possessions have shown their limitations: they may bring comfort, but they do not satisfy the mythic sense. They do not bring rebirth. A new car or a new house does not mean a new, more courageous or more interesting self. Now that the mundane limitations of life have to some degree been overcome, the radical impulse moves against the existential limitations of life. In this sense, the new morality is not so much a morality as it is a revolutionary manifesto against existential limitations-against the fact that we are mortal, that we are limited to one life, to one history, to one set of parents, to one sex, and to one body. The revolutionary impulse turns against the ego because this structure grows out of and is inextricably aligned with the basic, existential coordinates of reality. We saw that the aged turn against the ego in favor of magical mastery because their ego confronts them with the dread reality of their oncoming death. Like their elders, the young turn against the ego because it confronts them with limitations that they have come to regard as intolerable insults, as metaphors of death.

The old socialism required that all possibilities for material enjoyment be made available to all people; the new socialism of the affluent expresses itself in the desire to keep personal options open toward all life styles, toward all possibilities for experience, whether pleasurable or painful, "male" or "female," infantile or adult, constructive or criminal, sadistic or masochistic, human or even subhuman. The human ego is both a product and a creator of boundaries and distinctions, and so the new radical analysis, driven by the myth of the omnipotential self, defines the ego as counterrevolutionary: it stands in the way of the desired collectivization of experience and of life styles.

Thus many practices of the counterculture can be seen as revolutionary tactics against the "reactionary" ego. For example, drugs-and particularly the 
hallucinogenics-are Molotov cocktails against the inner boundaries of the ego. During the drug trip, one can have, in quite concrete ways, the illusion that one includes and is included in all the possibilities, all the agencies of existence, and that one has escaped the bondage of self. Thus one young acidhead describes holding a spoon during his trip, and he tells me that he becomes the spoon that he holds, looking back at himself, who holds it. He has escaped the limitation of a concrete, boundaried self. Other users tell me that they experience themselves as babies, as animals, even as gods.

By the same token, encounter groups serve to dissipate the sense of self-other boundary, particularly the sense that one is locked into one's own experience. Encounter groups advance the socialism of the affluent in the sense that they are in the service of the collectivization of consciousness. The goal of the encounter is not to discharge some troubling feeling for some therapeutic end. Rather, the sharing of flesh and of feeling is in itself the goal. In the group encounter setting, for a while at least, the inner contents of the psyche and the flesh that covers it become pooled, defined as collective property. In the Esalen-style settings, there is practiced a kind of id-communism, where distinctions between inner and outer, between self and other, between group and individual, are treated with the same disdain as traditional Marxists treat the distinction between state and private property. The important phrase that has come into the general culture from the encounter groups is "let me share this with you." Behind the group's demand for honest expression of feeling is the consumer's morality: "I want to savor the authentic stuff, the real feeling ..." Again, the goal is not to understand the other but to be the other and thus to escape the intolerable limitation of a single self..$^{3}$ The new dress styles and cosmetics play similar "revolutionary" functions. Dress symbolically wipes out a limiting history: it is as if the wearers of the new styles say, "I was born a middle-class WASP or Jewish boy-I have a history that already predicts and forecloses my future, but I will dress as if I were a Negro, a Hell's Angel, a cowboy, an Indian, a woman, or all of the above." Thus the hippie uses his collage of garments and cosmetics to symbolically incorporate all of those options which have hitherto been regarded by the square world as mutually exclusive. But the ego is not kind to the fantasy, "I am what I choose to wear," and so the ego becomes the enemy that stands in the way of self-realization in these illusory terms.

\section{THE SOCIAL EFFECT OF THE NEW MORALITY}

Thus the myths of the counterculture are an outgrowth, a translation, of

${ }^{3}$ The collectivization of consciousness is not limited to pleasant experiences. I was recently told of a California commune whose members kidnapped a dying patient from a nearby hospital so that they "could experience dying." 
the myths that led to what Eric Fromm and David Riesman have called the consumer society. The idea that one can own all good things in the form of material possessions has become the idea that one is all good things, that one contains all possible life forms and styles. Thus the young are still being inducted, via the counterculture, into the consumer society-only now they move into the consumption of life styles rather than the consumption of material goods per se. In this basic sense, the young continue to resemble the aged. In both cases, the youthful and the aged, the striving is toward omnipotence: the aged have relinquished the fantasy of personal omnipotence, and seek for some external alliance with omnipotent authorities, either secular or supernatural; and the young, whose omnipotent fantasies have not yet been reality-tested, still seek to find that all-containing, godlike figure within themselves. Accordingly, they exalt any chemical or, any practice that promises to unlock the door of their own inner sanctum.

We can consider the effects of the new morality from two angles, the social and the personal: on the social side, we can ask how wide is its effect; and on the personal side, we can consider the effects of the new morality on the psychological development of those who are attracted to it. As for the social effects, the returns are not yet in. We do not yet know if the new morality will appeal to all our youth, or only to the children of the WASP and Jewish elites who have thus far been most responsive to it. We do not know if we are faced with the "Greening of America" or with what has been called the "Blueing of America," the circulation of elites. The outcome will partly depend on the young themselves, but in some large part it will also depend on the degree of sponsorship that the counterculture gets from the adult sector of the society. And make no mistake: the counter-culture has received a surprising amount of adult support. Thus we find intellectuals sponsoring a culture that is determinedly antirational, and we find psychologists sponsoring a culture that puts itself quite explicitly on the side of narcissism, and even madness. It is ciear that I am not a partisan of the counterculture. at best I see it as a form of naiveté that has no viability; at the worst, it is a kind of aristocratic elitism, masquerading as revolution. But while I am against it, I can still understand its appeal for youth. Why should they resist cultural messages that ratify their fantasies of omnipotence and that urge them to eat their cake and have it too? What I cannot understand are my numerous academic colleagues who abandon the adversary stance that is a necessary part of teaching and endorse such messages. These adults protest that they are on the side of a youthful cohort that is experimenting with new and more human life styles. Perhaps so, but if that were indeed the case, these adults could best help youth by being teachers, by maintaining a critical stance, by pointing out rather than endorsing the various delusions that have wrecked most youthful attempts to establish new and viable life styles. When adults abandon the critical stance toward youth, 
they become not lovers, but saboteurs. Indeed, I begin to think that many adult sponsors of the counterculture, particularly those who are striving and achievement-oriented for themselves, may take some unconscious pleasure from the spectacle of passive, even geriatric young men, young men who have abandoned the traditional rivalry with the older generation.

At any rate, it seems to me that the counterculture and the new morality is not suigeneris a youthful phenomenon. Like most human events, it represents a collaboration between individuals or cohorts that are strongly bonded to each other in the emotional and developmental sense. It represents a collaboration, potentially destructive for each side, between segments of youth and their adult supporters. I think that much of it will phase out-and it is already beginning to-when pivotal adults withdraw their uncritical support.

\section{THE PERSONAL CONSEQUENCES OF THE NEW MORALITY}

Consistent with this critical role, my discussion of the personal consequences of the new morality will emphasize some of the negative effects for psychological development in adolescence. Many observers have already documented the fact that the new morality sponsors a greater sensitivity, a greater esthetic sensibility in the young that up to now has been underplayed in our culture. I agree, but I would assert that these particular gains bear a heavy price. For one thing, this greater openness is not the result of training but is bought at the price of firm ego boundaries. Regression in the service of the ego is a precondition of creativity if there is an ego to return to, one that can integrate the experiences that have been gained through temporary ego diffusion and turn them into insight and new data. But sensitivity that is founded on a chronic absence of ego boundaries leads to the bad trip as predictably as it leads to the good trip. When ego boundaries are low, we can experience the world as a picture of our own appetites and excitements: that is the good trip. But when ego boundaries are low, the world can as easily become a picture of our own fear, or our own bad internal objects, and that is the bad trip. The passive ego is at the mercy of the ambivalence that is intrinsic to all object relations; and if it finds good and consoling objects in the world it will as predictably find bad and terrifying objects out there. Thus the kids of the counterculture have to isolate themselves in rural communes, or dull their vaunted sensitivity with drugs and wine in order to blank out the pain, the ugliness, and the "death" that they constantly discover in the world. In their case, actual physical isolation, physical and chemical boundaries, have to substitute for the internal, autonomous ego boundaries that they have not constructed.

Thus the counterculture to some degree sponsors and is predicated on a kind of flabbiness of the ego. This is troubling in itself, but ego deficiencies during the pivotal period of adolescence also have important consequences for 
the adult stages of ego development, those which have to do with the roles of worker, spouse, and parent. Erikson has defined the stages of ego development that relate to these roles: they are, in their order of emergence, identity, intimacy, and generativity. In the following discussion, I will briefly consider the impact of the counterculture on these conformations of the ego.

\section{THE FLIGHT FROM IDENTITY}

Identity is an achievement of the ego, a creative act of the ego upon itself. Identity has roots in early preadolescent experience, and it is continually revised in the adult years; but a major consolidation in these terms takes place in adolescence. The formation of ego identity is not just a task that is set for adolescents by our particularly achievement-oriented society. It is a task set by life, by the universal fact of a human life cycle. Many pressures, inner and outer, stimulate the adolescent quest for identity, but a crucial factor has to do with the recognition of finiteness, of temporal limitation on the life span. We are most driven toward identity at the point when we come to realize that we have only one finite life cycle, when we recognize that there is not world enough or time to be everything, to know everything, to enjoy everything. At this point, one must reconsider one's omnipotent fantasies. We give up the idea of being everything in exchange for becoming, within our limits and potentials, the best thing that we can be. We look for some particularly worthy social perspectivewhether healer, scientist, builder, or revolutionary-some calling that, as we see it, needs to be served, that we can serve, and that will sponsor the development of our best potentials. In effect, in the course of choosing an identity we give up omnipotence in exchange for uniqueness. True, the responsibility for the identity crisis of our time is not located solely within the young: modern urban society by its very nature makes the identity choice very difficult. The skeptical, secular spirit of the times portrays all life-ways as being potentially ridiculous, if not actually corrupt. Few, if any, carry the mythic aura, the sense of being centers of wholeness and excellence that would justify the sacrifices that they require of their adherents. Thus when the adolescent "candidate" for identity looks out on the vast smorgasbord of potential identity choices that he is confronted with, he is hard put to find one that is worth standing for, that is worth the sacrifice of narcissism that is fundamental to identity choice. Faced with the difficulty of choice, most adolescents try to extend the moratorium on choice: they go to college, they go into the army, they bum around for a while and consider the possibilities. Some particularly obsessive adolescents refuse to make even the preludes to choice, and remain in the negative alternative to ego identity-the position of role diffusion. They refuse to be anything and thus retain the fantasy that they could be everything.

Granted, then, that it is difficult under the best of circumstances to form a 
satisfactory identity in our time. But the new morality adds an extra and potent complication. The here-and-now emphasis of the counterculture and the new morality acts against the future orientation, and thereby retards the adolescent's recognition that he has a life cycle, and that it has already begun. He is buffered from the need to make some final choices, including the choice of an identity.

Furthermore, the new morality serves the socialism of the affluent rather than the cause of identity. Its message to the adolescent is: "You are doing the proper and even revolutionary thing by not making a choice, by keeping all options open, by refusing to surrender any of your possibilities." In effect, the new morality and the counterculture act so as to institutionalize role diffusion. The position of role diffusion takes on a moral bonus: role diffusion comes to be regarded as a moral choice, and thus takes on the status of an identity possibility. The adolescent can enjoy the moral bonus that usually comes with the achievement of identity without having made the hard choices and the sacrifices of narcissism that are intrinsic to identity formation.

The apologists for the counterculture argue in effect that this is a viable solution, that role diffusion deserves the status of identity, and should be presented to the young as such: "So long as they're happy, why rock the boat?" This could be an adequate answer if there were no life cycle. But the kids do grow older. During the experimentation with role diffusion, they indulge fantasies, often abetted by drugs, of their uniqueness, but at the expense of the inner resources, the ego executive powers that they could be developing through meeting some refractory piece of reality. At some point, the fantasy of uniqueness is tested; and without real resources to back it up, it is usually refuted. Role diffusion only defers the narcissistic wound, it does not finally avert it.

The idea that role diffusion can be legislated into identity reveals its weakness when the postadolescent realizes, often with mingled range and panic, that he has no veto power over the passage of time. Despite his obsessive efforts to control time, the clock has continued to tick, and to measure out his life. He thought that he was playing around, deferring choice, keeping all possibilities open. Yet it turns out that the very refusal of choice was in itself a choice, one that delimits and even cripples his future. As one postadolescent patient of mine put it, "I thought that I was holding the train in the station; but all the time it has been rolling along, towards the ruined bridge..." It is at this point that many postadolescents have an experience of irreversibility. Bad things have happened to them; it is too late and too wearisome to attempt a new beginning, and the bad past promises a bad future. As at the end of life, among the aged, the future is seen to be irrevocably compromised and foreclosed. The young may develop, prematurely, the disgust or despair that Erikson has described as the lethal ego state of aging, at the end of life. At this point, they may turn, quite suicidally, to the use of hard drugs. 


\section{INTIMACY WITHOUT LOSS}

Suicide, clinical symptoms, and drug addiction are extreme solutions to the pervasive identity problems of our time. More usually, unresolved identity problems reveal themselves as difficulties in the next stage, of intimacy. Identity gives us the autonomy from others that is necessary to a full commitment to some unique other. The attainment of identity roots us in some transcendent ecology: it roots us in the past and in the future, in a creation of the mind that travels with that mind. It is an inward assurance of inclusion and belonging that does not rest on any particular, tangible group, and so cannot be lost. The existential risk in intimacy is that, having come to love some unique other, we will lose that other. The risk of loss is not easy to face unless we have the assurance, gained through the achievement of identity, that there is something final and trustworthy that we will not lose.

In the counterculture-as we have seen-the attempt to achieve the internalized certainty of an identity is abandoned or delayed. Furthermore, the sequence of identity then intimacy is reversed, and the attempt made to achieve intimacy before identity, or to turn intimacy into a substitute for identity. In the counterculture, the illusion is maintained that human relationships could give some final assurance, some final security. But friends and lovers cannot be guaranteed against loss; a sense of security founded on relationships alone will always be vulnerable. Accordingly, intimacy cannot substitute for identity, and the consequence in our time, and particularly in the counterculture, is a massive turn toward various forms of pseudointimacy-those which allow for transient contact, but which also avoid the risk of loss, the tragic dilemma of true intimacy. Thus we now have the mock intimacy of encounter groups, where secrets are shared with anonymous strangers; or where individuals are reduced to the impersonal, easily replaced parts of themselves-lips, tongues, hands, genitals-that are involved in the provision of sensual pleasure. Intimacy is attempted with the group, or with some sexual part-object: all those versions of the other that can be replaced. Perhaps for similar reasons, divorce rates have increased tremendously. The marriage ceremony states, "Till death do us part," and reminds the nuptial couple that the commitment to intimacy must be made in the full knowledge that one spouse will witness the death of the other. Without clear identity, such a drastic commitment to marriage becomes hard to accept. Serial marriages, adultery, open marriage, and group marriage are all sought as ways out of the dilemma: they are ways of reducing the vulnerability to loss. But in the name of a risk-free, painless intimacy they lead finally to the lonely crowd, to essential isolation within the outward forms of intimacy.

\section{GENERATIVITY AND NEW LIFE STYLES}

Generativity, the central stage of adulthood, may be the most important 
casualty of the myths and morality of the counterculture. Erikson $(1959$, p. 97) has defined the stage in these terms: "Generativity is primarily the interest in establishing and guiding the next generation, although there are people who, from misfortune or because of special and genuine gifts in other directions, do not apply this gift to offspring but to other forms of altruistic concern and creativity, which may absorb their kind of parental responsibility." He adds, "No other fashionable term, such as creativity or productivity, seems to me to convey the necessary idea."

Clearly, Erikson is describing more than dedicated child-care: he is describing a mode of caring that generalizes to all the aspects of generation, to all the ways in which new individuals, new works, new institutions, and even new life styles are conceived and nurtured through their periods of early vulnerability. Such caring requires not only warmth and good intentions; it requires a disciplined capacity to surrender personal claims-for comfort, for security, for self-expression-in the name of whatever new thing is being created. Thus parents have to concede some of their own future aims to their children, who are the inheritors of the future; and they have to learn to control their own angry reactions-often the residues of their own sibling rage-toward a fretful, continually demanding infant. By the same token, a creative artist cannot see in paint or stone only a vehicle for his own self-expression; if he is really good, then he must see himself as the vehicle whereby paint or stone or clay finds its best possible form. The medium is not there to release him; he is there to liberate his medium. The point is that creators or "generators" have to rely on more than some quickly expended creative impulse or excitement if they are to make viable the children, the art, or the institutions that they have initiated. The future is the proper ecology of fantasy, and hence the new being or the new event, that which inhabits the future, can easily justify latent narcissistic fantasies of some final perfection that is to be brought into being. Such fantasies can mobilize much energy and high morale during the initial frenzy of creation, but more durable and trustworthy motivations have to take over once the new child, the new art form, or the new politics begins to reveal its inevitable flaws. It is at that point that the newly generated thing must be loved for itself, as an object, and not as an expression of the creator's unrelinquished narcissism.

The counterculture is very good at sponsoring the initial, self-expressive fantasy-driven excitement. The new act, the new enterprise means new experience, it offers the possibility that the self will become more inclusive; the new enterprise thereby serves the myths of affluent socialism and thus receives much logistical support from the easily mobilized "armies of the night." But the counterculture does not sponsor the difficult switch from self-expression to true generativity. As soon as new politics or new communities reveal their inevitable flaws or contradictions, they can no longer maintain the illusions of perfection or perfectability in their adherents. As a consequence, the new institutions are 
either abandoned, or given over by default to the megalomaniacs and psychopaths who accompany the countercommunities like sharks after herring. The counterculture has, in the decade of its existence, produced many exciting beginnings, but very few persistent, viable life styles: the communes have folded or have degenerated toward authoritarianism; Haight-Ashbury (like other urban enclaves of the new life styles) became in two years an authentic circle of Hell; and the original life-serving religious vision has become the authoritarian mindlessness of the Jesus Freaks and the Hari Krishna skinheads.

The counterculture is trapped in the politics of narcissism, in the boundaryless perspective which says, "What feels good for me must feel good for others," and therefore cannot author a new generativity based on the priorities of whatever new and vulnerable thing is emerging. The apologists for the counterculture deal with such criticism by claiming that their singular contribution has been to revise the standards for creativity: production has been redefined as an act of joy, and no longer requires delay of gratification, future orientation, or linear thinking. But the productive style that is identified with capitalism, and that was routinized under capitalism, is not an invention of capitalism. Delay, self-discipline, forethought are essential to any form of generativity. They are not only necessary to the capitalist entrepreneur; they are also necessary (though admittedly not sufficient) to the business of raising a viable child, creating a new art form, a new life style, or a revolutionary movement. Thus in discarding the productive orientation as bourgeois and life-denying the counterculture has also thrown away generativity-and with generativity it has thrown away the future.

The stages of identity, intimacy, and particularly generativity pose a common threat which goes beyond the requirements and demands of any particular stage: these ego positions imply that one has become adult, that one has therefore entered the life cycle, and that one will eventually die. To enter life fully, to begin, is also to accept the reality of the end. Thus to become a parent is to accept the fact that we have prepared the generation that will outlive us, the offspring who-if all goes as it should-will preside at our funeral. ${ }^{4}$ Accepting the stages of adulthood, we accept a deep narcissistic wound: we have gotten on the train, the train is moving, and its final destination is known. In the words of my patient, the track ends at the ruined bridge; and if we could change that fate by an effort of mind and will, then the new morality would be justified. But we cannot; and the consequence of the new morality is not to defer the train wreck, but often to bring it closer. I have tried to suggest that the outcome of the new morality is not rebirth and revival, but its opposite: a kind of premature presenility. The new youth are obsessed with death: they see

${ }^{4}$ Thus the traditional Jew refers to his first son as his "Kaddish"-he calls him by the name of the prayer that is read over the dead father by his eldest son. 
metaphors and threats of death everywhere. I submit that this is not because they live in a dying world, but because they themselves, in the psychological sense, already stand too close to the end.

Deny it as we may, there is a life cycle, and it has its seasons. There is a time to be a child, and a time to give up the ways of a child. In attempting to hold on to childhood and the prerogatives of the child, the counterculture and the new morality deprive youth and youthfulness of its proper season, and instead being on a premature aging.

\section{REFERENCES}

Brown, N. O. (1959). Life Against Death: The Psychoanalytical Meaning of History, Random House, New York.

Decter, M. (1972). The New Chastity, Coward-MoCann, New York.

Erikson, E. (1959). Growth and crises of the healthy personality. Psychol. Issues 1:1.

Goldstine, T., and Gutmann, D. (1972). A TAT study of Navajo aging. Psychiatry 35:373.

Gutmann, D. (1964). An exploration of ego configurations in middle and later life. In Neugarten, B. (ed.), Personality in Middle and Later Life, Atherton, New York.

Gutmann, D. (1966). Mayan aging-A comparative TAT study. Psychiatry 29:246.

Gutmann, D. (1967). Aging among the Highland Maya: A comparative study. J. Personal. Soc. Psychol. 7:28.

Gutmann, D. (1969). The country of old men: Cross-cultural studies in the psychology of later life. In Donahue, W. (ed.), Occasional Papers in Gerontology, Institute of Gerontology, University of Michigan, Ann Arbor.

Gutmann, D. (1971). The hunger of old men. Transaction 9:55.

Gutmann, D. $(1972 a)$. The premature gerontocracy: Themes of aging and death in the youth culture. Soc. Res. 39:416.

Gutmann, D. (1972b). Aging among the Highland Druze. Unpublished paper, presented at 1972 Meetings of the Gerontological Society.

Krohn, A., and Gutmann, D. (1971). Changes in mastery style with age: A study of Navajo dreams. Psychiatry 34:289.

Marcuse, H. (1962). Eros and Civilization: A Philosophical Inquiry into Freud, Vintage, New York. 